\title{
"Pela minha família, voto sim": o uso dos valores tradicionais da família na cena política brasileira ${ }^{1}$
}

\author{
Belinda Mandelbaum ${ }^{2}$
}

Nos últimos anos do século XX e neste início de século, assistimos em diversos lugares do mundo ocidental a um movimento expressivo, que ganha espaços na cena pública, nas ruas e nas redes sociais, de reação a conquistas sociais de grupos tidos como minoritários. Em muitos países, políticos reacionários ganham apoio popular. Suas bandeiras incluem a xenofobia, a ideia de superioridade e hegemonia nacional, o preconceito religioso, étnico e de gênero. É difícil neste espaço citar todas estas manifestações, do ganho de posições políticas a movimentos de massa, da mídia à internet, mas é significativo lembrar que diversos autores, no campo da Política e da Cultura, têm sinalizado a emergência de uma nova onda reacionária no mundo, com retrocessos importantes do ponto de vista das conquistas sociais por igualdade de direitos.

No Brasil, assistimos nos últimos anos à ascensão de políticos, em boa parte ligados a igrejas neopentecostais, que pregam junto à população uma moral e uma conduta que coloca a família, em sua diversidade de arranjos, no centro da disputa política. A sentença "pela minha família, voto sim” justificou a maior parte dos votos favoráveis ao impeachment da presidenta Dilma Rousseff na Câmara dos Deputados, em abril de 2016. Os interesses do país e de toda a população foram reduzidos a interesses pessoais e privados, familiares e domésticos. E na mesma toada, assim que assumiu a presidência, Michel Temer declarou que "o governo é como sua família. Se estiver endividada, precisa diminuir despesas para pagar dívidas. Por isso, uma de nossas primeiras providências foi impor limites para os gastos públicos" ${ }^{3}$. Nessa família dele, parece haver lugares bem definidos, sobretudo para as mulheres. Sua esposa, Marcela Temer, "bela, recatada e do lar", assumiu o posto de embaixadora do Programa

\footnotetext{
1 Este trabalho foi apresentado na mesa ““"Mal-estar na família” com Regina Maria Rahme no I Simpósio Bienal "O mesmo, o outro: Psicanálise em movimento" da Sociedade Brasileira de Psicanálise de São Paulo.

${ }^{2}$ Psicanalista, professora associada e chefe do Departamento de Psicologia Social e do Trabalho do IPUSP, coordenadora do Laboratório de Estudos da Família, Relações de Gênero e Sexualidade.

3 Pronunciamento feito em 31 de agosto de 2016. Disponível em: https://www.youtube.com/watch?v=ZANH1Ik9iwA
} 
Criança Feliz, reafirmando assim o lugar feminino ligado ao cuidado e ao afeto em um trabalho voluntário e vocacional - uma presença "que visa incentivar as senhoras mulheres do país", acrescentou o presidente na ocasião.

Nesses discursos de representantes de nossa sociedade, um único modelo de família é legitimado e defendido como moralmente superior: a união entre um homem e uma mulher e seus filhos, apresentada a um só tempo como natural e como expressão da Vontade Divina. Ecoando, claro, vozes de diversos setores da sociedade brasileira, estes discursos reagem às conquistas sociais anteriores, são contrários aos direitos das mulheres e dos movimentos LGBT e desconsideram a pauta dos direitos humanos como norte das políticas públicas. Tratase de um empenho de tutela do Estado sobre a intimidade das relações afetivas que cria hierarquias morais entre elas e busca jogar na imoralidade milhões de famílias brasileiras que não correspondem ao modelo preconizado. Para se ter uma ideia do que estamos dizendo, em mais de 50\% dos domicílios no Brasil o IBGE, desde 2006, não encontra o modelo da família nuclear tradicional, sendo estes habitados por famílias extensas, monoparentais, pessoas que vivem sozinhas ou com amigos, casais homoafetivos, etc.

Uma possibilidade de definir a(s) família(s), reconhecendo esta diversidade, é tomar em consideração e respeitar a dignidade do modo como cada um concebe a própria família, ou seja, o conjunto de pessoas que chama para si de família. Em oposição a isto, uma comissão especial do Congresso Nacional aprovou em caráter conclusivo, em outubro de 2015, o Projeto de Lei 6583/13, conhecido como Estatuto da Família. De autoria do Deputado Anderson Ferreira (PR-PE), este Estatuto define o que é família - a união estável entre um homem e uma mulher e seus filhos ou um dos genitores e seus filhos -, impondo assim um único modelo, uma só forma de vida a estabelecer as diretrizes das políticas públicas no país. É uma pá de cal não apenas sobre as conquistas sociais, mas também sobre o conhecimento acumulado mundialmente, no campo dos estudos de família e parentesco, quanto à multiplicidade dos arranjos familiares existentes. O Estatuto propõe que apenas os membros das famílias que cabem em sua definição teriam a garantia da proteção do Estado no tocante à saúde, educação, assistência social, previdência, moradia, etc, estabelecendo assim uma hierarquia de direitos entre os brasileiros e brasileiras, em todos os âmbitos.

Amparando-se na Constituição de 1988, que define a família do mesmo modo, lê-se no texto do Estatuto da Família que este "vem para colocar a família, base da sociedade, credora de especial proteção, no plano das políticas públicas, de modo sistemático e organizado, como 
até então não se fizera" (BRASIL, 2015, p. 11). Ou seja, o Estatuto coloca as famílias que compartilham do modelo preconizado sob proteção especial enquanto destitui de direitos todas as outras, em um processo de precarização e vulnerabilização da vida de milhões de pessoas. Propõe um só modo de ser como sendo a verdade da família e, neste sentido, age de forma totalitária e antidemocrática. Legitima o preconceito, a violência, a punição e a culpabilização de quem não compartilha o modelo. Como destaca Drezett (2015), o Estatuto da Família "pretende, com base na crença, estabelecer um limite religioso para definir a família por força de lei, desafiando e desrespeitando os princípios do Estado laico, democrático e de direito" (p.1).

É sabido que o século XX assistiu a diversas mudanças importantes na família, em sua composição, em suas funções e em sua dinâmica. Após as duas grandes guerras mundiais e as matanças de proporções exponenciais que produziram, o mundo ocidental teve que fazer face a um questionamento profundo de seus valores, de seus modos preconizados de viver, de organizar-se política e socialmente, daquilo que até aquele momento chamava-se progresso e civilização. As instituições tiveram que ser e foram efetivamente repensadas, tendo em vista o seu potencial autoritário, hierárquico e destrutivo, gerador de sofrimento psíquico e social. No campo das Ciências Humanas, diversos autores foram no pós guerra porta-vozes do que Paul Ricoeur (1965/1977) chamou de hermenêutica da suspeita, uma intensa atividade crítica que desnudava a barbárie e a crueldade de instituições e práticas sociais até então hegemônicas. Freud, em $O$ mal estar na civilização, já em 1930 denunciava o poder adoecedor da civilização, as "relações do homens na família e no Estado" como uma das fontes da infelicidade, juntamente com o poder destrutivo da Natureza e as exigências e transtornos do próprio corpo. Franz Kafka, em diversos de seus textos, desnudou o poder autoritário desde sua origem na figura paterna e em sua ação no interior da família, apontando sua faceta irracional, hipócrita e violenta. Um de seus escritos, a Carta ao pai (1919/2004), foi um dos principais textos do século XX a colocar em questão a superioridade da família centrada no poder paterno. A Psicanálise também não escapou de suspeita, como discurso normatizador da sexualidade e da família. E toda a Escola de Frankfurt, no período entre guerras, apontou para a crise das instituições burguesas a partir de uma perspectiva que integrava seus fundamentos econômicos e psicológicos, a estrutura socioeconômica e seus impactos psíquicos, utilizando para suas análises concepções centrais da teoria marxista e da psicanálise freudiana. 
O modelo tradicional da família burguesa esteve no centro destes questionamentos. Sua composição - o casal heterossexual e seus filhos constituindo uma unidade doméstica independente, com limites claros entre o espaço privado e o espaço público -, sua forma de organização - centrada na autoridade paterna, no pai como provedor, na mãe como responsável pelo cuidado da casa e dos filhos, com clara hierarquia entre o marido e a esposa e entre os pais e os filhos - e sua função - a reprodução, na educação dos filhos, dos valores e das relações de autoridade da sociedade burguesa, centrada nos modos de produção e de relações humanas no trabalho próprias do sistema capitalista -, tudo isto passou por uma crítica profunda. De modelo ideal, naturalizado e inquestionável, a família nuclear tradicional passou a ser apontada como instituição histórica, repressora, reprodutora da violência social e produtora de doença mental. A partir dos anos 50 do século XX, diversos autores - lembro aqui Ronald Laing, David Cooper, Gregory Bateson, Isidoro Berenstein, Janine Puget, Luiz Meyer entre nós - nos ajudaram a compreender o adoecimento mental não mais apenas a partir do exame do indivíduo em sua dimensão intrapsíquica, mas que era preciso pensá-lo como parte do conjunto de relações humanas cujo centro irradiador é a família. O grupo familiar passou a ser visto como psiquicamente responsável pela produção do adoecimento, seja em função dos modos de comunicação e/ou incomunicabilidade que estabelece ou pelos limites em sua capacidade de acolher e pensar as angústias de seus membros, ou ainda por seu potencial para permitir ou impedir o desenvolvimento e a independência de seus membros. A família passa a ser questionada em sua potência para fazer sofrer e enlouquecer, para além de suas possibilidades de cuidado e proteção.

O questionamento da família nuclear tradicional como modelo superior universal, como parte da ordem natural e fruto da Vontade Divina, recebeu também importantes aportes dos conhecimentos advindos dos estudos do parentesco iniciados em fins do século XIX, e de seus desdobramentos até meados do século XX. A suspeita que recaiu sobre os modelos hegemônicos no ocidente impeliu pesquisadores a conhecer outras formas de organização social. Etnólogos evolucionistas já em fins do século XIX descreveram a diversidade de arranjos familiares no mundo alocando-os numa linha que partia de agrupamentos sociais sem uma organização familiar reconhecível, evoluía para o matriarcado, o patriarcado e culminava na família nuclear. Há diversas críticas a esta perspectiva no campo dos estudos do parentesco: basicamente ela é eurocêntrica, ao afirmar o arranjo familiar predominante nas cidades do Ocidente como o ápice da civilização e do progresso, estabelecendo uma hierarquia entre famílias ditas primitivas e outras, evoluídas. É uma perspectiva colonialista, 
tende ao preconceito e ao exercício violento da doutrinação de alguns povos sobre outros. Mas, ainda assim, diz Lévi-Strauss (1956/1986) que os etnólogos evolucionistas tiveram o mérito de introduzir, nos estudos de parentesco, a História no reino da Natureza. Ou seja, afirmaram que a família não é nem natural nem emanação da Vontade Divina, que é instituição na intersecção entre História e Natureza, entre a Cultura e a Biologia, e que seus arranjos não são universais - ao contrário, estão intimamente articulados às formas de organização econômica, social, cultural de cada agrupamento humano. Sabemos desde o século XIX, graças a estes estudos, que as famílias mudam, são instituições históricas variáveis, portanto, no tempo e no espaço. Lévi-Strauss, por volta dos anos 1950, a partir de dados etnográficos recolhidos por pesquisadores em diversas sociedades e reunidos em sua obra As formas elementares do parentesco, contrapôs a perspectiva evolucionista ao mostrar que, do ponto de vista das estruturas de parentesco, famílias no mundo têm muito mais em comum do que à primeira vista pode parecer. Sem perder a perspectiva da diversidade nos arranjos familiares, ele mostra no entanto que o arranjo nuclear, tido até então como próprio das sociedades mais civilizadas, está presente também em agrupamentos sociais considerados primitivos, da perspectiva evolucionista, quanto ao seu desenvolvimento econômico e tecnológico. Ou seja, as Ciências Humanas no século XX, após duas grandes guerras, e como parte do questionamento das formas hegemônicas de organização social no mundo ocidental, deram voz e legitimidade à diversidade dos arranjos familiares, fazendo cair por terra certa ideia de família como ordenamento natural e universal, ou fruto da Vontade Divina.

Cabe a nós tentarmos compreender, ainda que de forma fragmentária e parcial, o sentido do debate sobre a instituição familiar hoje, tal como se manifesta no centro da cena política neste momento da vida nacional, a partir de um exame que leve em consideração diversas dimensões do contexto em que este debate vem ocorrendo. Do ponto de vista econômico, o governo brasileiro opta neste período por uma política corte de gastos públicos como um dos encaminhamentos necessários para o saneamento da economia. Em um momento em que se parece retomar a noção original de economia enquanto "sábio governo da casa para o bem comum de toda a família" (FOUCAULT, 2008, p.126), é isto que se preconiza: que no governo do Estado se instaure um olhar atento como aquele que um pai de família tem sobre sua casa e seus bens. Mas também, ao longo de nossa história, de modelo de governo, a família se tornou instrumento para ele, de forma a garantir o controle da população, cujos fenômenos e manifestações evidentemente não se reduzem aos da família. O Estatuto da 
Família, ao definir critérios para as famílias que terão acesso a direitos sob a proteção do Estado, retira desta proteção grande parte da população brasileira, isto é, corta gastos.

Do ponto de vista moral, os políticos, sob acusação de imoralidade no trato da coisa pública, de evidências de corrupção em todos os níveis, de favorecimento de interesses particulares em detrimento da nação, buscam desviar, com o debate sobre o Estatuto da Família e uma pregação incessante e fundamentalista contra todos os que divergem de suas verdades, o foco da imoralidade para as famílias dos brasileiros, passando a sermos nós os imorais e eles, os bastiões da moral e dos bons costumes. Em uma sociedade profundamente influenciada hoje por discursos religiosos deste mesmo cunho fundamentalista, esta pregação dá voto. E a defesa da família tradicional - com a retomada de lugares hegemônicos para homens e mulheres que são produtores de intensas e violentas desigualdades de gênero - se mostra a serviço do esvaziamento da experiência coletiva, democrática e protetiva em nosso país, experiência esta já instável e precária, uma vez que o Estado brasileiro sempre afiançou poucos direitos à sua população.

Diante do obscurantismo reinante, parece-nos restar lançar algumas luzes sobre essa "onda" reacionária, inclusive para perguntarmo-nos se será que podemos tratar como "onda" um reacionarismo estrutural e histórico em nosso país que, sob diferentes vestes, é sempre ágil em impedir e fazer retroagir as conquistas sociais quando estas ameaçam dar alguns passos - em particular aqui em seus efeitos sobre a família contemporânea. Confiamos que estas luzes, ainda que tênues, possam contribuir para guiar passos da sociedade brasileira em direção a práticas democráticas de cuidado com todas as nossas famílias.

\section{Referências}

Drezzet, J. A quem interessa o Estatuto da Família? Reprodução \& Climatério. Vol. 30, n. 1, janeiro - abril 2015.

Estatuto da Família (Brasil, 2015). Projeto de Lei 6583/13, autoria do Deputado Anderson Ferreira.

Foucault, M. Segurança, território, população. SP: Martins Fontes, 2008.

Freud, S. (1930). O mal-estar na civilização. Obras Psicológicas Completas de Sigmund Freud, v. XXI. RJ: Imago, 1976.

Kafka, F. (1919) Carta ao pai. SP: Companhia das Letras, 1997. 
Lévi-Strauss, C. (1956) A família. Em Lévi-Strauss, C. O olhar distanciado. Lisboa: Edições $70,1986$.

Ricouer, P. (1965). Da interpretação: ensaio sobre Freud. Rio de Janeiro: Imago, 1977. 